\title{
Validity and Reliability of Penalty Stroke Tests in Hockey Games for Junior High School Students
}

\author{
Rikky Ridwan* \\ Program Studi Pendidikan Olahraga \\ Universitas Pendidikan Indonesia \\ Bandung, Indonesia \\ *rikkyridwanhockey@gmail.com
}

\author{
Angga M. Syahid \\ Departemen Pendidikan Kepelatihan Olahraga \\ Universitas Pendidikan Indonesia \\ Bandung, Indonesia
}

\begin{abstract}
A penalty shot often determines the team's success in winning. Penalty skills are needed because they have a role and contribution to the success of the team to achieve victory if the match is held in the match-making competition. The purpose of this study is to standardize and cultivate a measuring instrument that can be used to measure the ability to shoot penalties in sports hockey games specifically for junior high school students with the form of testing there are 3 types that have been tested on students. This study uses a Research and Development approach. The sample of this study was students of SMP 50 Bandung who participated in 30 hockey extracurricular activities. The conclusion of the study, that the forms of tests 1 and 3 have a lower level of validity and reliability than the form of test 2 , so that the test form is not good to be used as a test of accuracy of penalty shots for junior high school students, while the test form 2 is more feasible and meets the criteria for used as a measure for testing the accuracy of penalty shots for junior high school students in hockey sports.
\end{abstract}

Keywords—validity test; reliability test; hockey penalty stroke

\section{INTRODUCTION}

Hockey sports have long been known by some of the world community. Only developed in the community of schools and colleges, the public is not so familiar with hockey. The population of hockey players in Indonesia is still limited, but there have been many championships both regional, national, regional, and competitions held in the school environment, especially among High School (SMA) and Higher Education (PT), whereas in elementary schools (SD) and junior high schools (SMP) began to be developed with modified facilities, infrastructure and rules. In hockey sports there is an ability that can contribute to the success of a team, this ability is related to the skill of athletes in taking advantage of the opportunity to shoot a penalty [1]. A penalty shot is the easiest way to score, because there are many possibilities for incoming balls. This is because an attacking player will only face the goalkeeper to score. A penalty shot often determines the team's success in winning. In addition, it is not uncommon for parties that are very decisive in hockey games such as when the final can occur on penalties where if the game time is up and the score is still strong then the penalty shootout is carried out, where the team is prepared to shoot penalties will be the champion, The ability to score from penalty corners can be the determining factor in winning a match $[2,3]$.
Penalty strokes are given due to mistakes made in D or striking circles if a player who defends clearly prevents a ball from entering in an unjustified way. Penalty strokes are carried out from a distance of $6.40 \mathrm{~m}$ from the front of the goal.

Penalty skills are needed because they have a role and contribution to the success of the team to achieve victory if the match is held in the match-making competition. Penalty shooting skills tests have advantages and disadvantages, the advantages of which are that the test describes aspects of hockey play and can describe the level of skill in the game of hockey [4]. However, the test has disadvantages, namely the validity and reliability level. Then the measuring instrument must be objective so that it will be easier for a teacher or trainer to assess and know the skill level of each athlete and to classify the athlete's ability to facilitate the training process. Previously, the form of the penalty shot test in hockey sports had been tested on students and had validity and reliability [5]. Whereas in junior high school students there has not been a specific form of test of the penalty shot. College Students and Middle School students must have different characteristics. In the form of other tests such as knowing VO2Max there are norms that are different for each age level. There are 3 types of penalty tests used by college students, namely the 1 st penalty shot test by placing the highest score of 5 (five) in the upper left corner and lower right corner, this is that most of the incoming shots are towards the left corner top and bottom right corner [6]. The second penalty shot test was a penalty shot based on goalkeeper range. "For the shots to the right the stick and left glove are used to save to left" [7]. This statement indicates that a goalkeeper will use his stick and glove to hold the ball to the right of the goal and the goalkeeper will only use the glove when the ball is towards the left of the goal. It can be assumed that the possibility of a goal to the left of the goal is greater than the right area of the goal, because if the ball is directed to the left area of the goal the goalkeeper will only use the glove. This makes the highest score placed on the left side of the goal. The third penalty shot test is a penalty shot test that makes the test by dividing the goal into 15 equal shooting areas, and placing the highest score of 5 (five) [8].

From the 3 forms above, the test will be returned to junior high school students. Which is the most permanent form of the penalty test above for use in middle school students. Therefore 
this research is to find out the validity and reliability test of the penalty shot test in hockey in junior high school students.

\section{METHOD}

This research was carried out using the "Research and Development" approach. The sample of this study was students of SMP 50 Bandung who participated in 30 hockey extracurricular activities. The measuring tool that I use in this study is:

- First test penalty shot is by placing the highest score of 5 (five) in the upper left corner and right corner, that most of the incoming shots are towards the top left corner and the lower right corner.

- The second penalty shot test is to test a penalty shot based on range kipper, "For the shots to the right the stick and left glove are used and glove save to left" [7]. This statement indicates that a goalkeeper will use his stick and gloomy to hold the ball to the right of the goal and the goalkeeper will only use the glove when the ball is towards the left of the goal. It can be assumed that the possibility of a goal to the left of the goal is greater than the right area of the goal, because if the ball is directed to the left area of the goal the goalkeeper will only use the glove. This makes the highest score placed on the left side of the goal.

TABLE I. TEST FORM SCORE 2

\begin{tabular}{|l|l|l|l|l|}
\hline 4 & 2 & 0 & 3 & 5 \\
\hline
\end{tabular}

- The 3rd penalty shot test is a test of Yanuar's penalty which makes the test by dividing the goal into 15 equal shooting areas, and placing the highest score of 5 (five).

Regarding the shooting position the entire penalty shot was carried out at the hockey field penalty which was $6.4 \mathrm{~m}$ from the goal.

\section{A. Purpose}

This test aims to measure the ability to get the right penalty shot in a hockey game.

\section{B. Tools and Equipment}

Hockey field, 5 (five) hockey balls, one hockey stick, mine, forms and stationery.

\section{Procedure}

- Every 1 (one) item test is given a chance of 5 (times) to shoot and from 5 (five) opportunities the value taken is the number of scores achieved by the test takers based on the scores of each target area that has been determined previously.

- At the command ready, the test taker stands near the ball and faces the target, the way to do it is in accordance with the provisions of the penalty shootout rule [9].

- On the cue, the ball was immediately shot towards the target. And so on until the test takers shoot five times.

- The duty of the supervisor is to observe the entry of balls in the target area and report to the note taker.

- If the ball is out of the target area (goal) then the score is 0 (zero).

- If the ball is about the bounding rope, then the score taken is the highest score

- Numbering on the instrument with the shape of the goal will determine the achievement of the value of five shots towards the instrument that has been given a line, with the shape of a box and in the form of different points from each instrument

The duty of the supervisor is to observe the entry or absence of the ball into the target area and mention the score obtained by the participant.

\section{RESULTS AND DISCUSSION}

\section{A. Result}

The sequences of calculation results will be adjusted to the procedures written in the section above. The results of data processing will be presented in detail as follows:

\section{B. Results of Calculation of Validity of Test Forms}

To find the validity of each form of ice, the writer first sets the criteria as a comparison. The criterion score is the combined result of the scores, obtained from the 3 forms of penalty shot tests that the author did.

From these values all are worthy of being used to measure the accuracy in shooting penalties for hockey players, because if seen from the list of distribution tables $\mathrm{t}$ for $\alpha=0.005$ and degrees of freedom $\mathrm{dk}=\mathrm{n}-2=30-2=28$, then table is 2.763 . The decision rule is tcount $>$ ttable means that all forms of the test (valid) can be used to measure the penalty shot of a hockey player.

\section{Results of Test Reliability Forms Calculation}

To find the reliability of each test item, the author did it by means of a test-retest. Namely by testing each form twice. After that the author correlates the results with the "product Moment" correlation formula. The results of the calculation of reliability for each test item are as follows:

Based on the results of the reliability calculation of all forms of reliable tests to measure the accuracy in shooting penalties for hockey players, because if seen from the list of product moment ( $\mathrm{r}$ ) for $\alpha=0.005$ and $\mathrm{dk}=\mathrm{n}-2=30-2=28$, then $r$ table is 0.478 . Decision rules are $r$ count $>r$ table means 
that all tests are tested reliably to measure the accuracy in guessing penalties.

\section{Discussion}

Starting from the aim of the research that was conducted was to test the shape of the penalty shot test, it must be known in advance how much the validity and reliability of the penalty shot test. Especially in terms of measuring the accuracy of penalty shots in hockey sports, so that later the test forms met can be used as a form of appropriate test to be used as a form of testing the accuracy of penalty shots for students. The results of the testing of the three forms of tests performed on the penalty shot test, at first glance there is not much difference in the scores obtained, from each member of the sample and each item test, this shows that the sample members take each penalty shot seriously and with his best ability.

Judging from the validity calculation, each form of proper test is used to measure the accuracy in shooting penalties for hockey players, including form 1, which explains that most of the blows that go in are towards the upper left and lower right corner [6]. Form 2 is based on the reach of the keeper [7] and form 3 made by Yanuar [5]. Of the three forms of tests can be used to measure the accuracy of the shot penalty for hockey players because it shows a fairly high level of validity.

Based on the results of the calculation of the reliability of all forms of reliable tests to measure the accuracy in shooting penalties for hockey players, from form 1 , which explains that most of the incoming shots are towards the upper left and lower right corner [6]. Form 2 is based on the reach of the keeper [7] and form 3 made by Yanuar [5]. Of the three results of the test form can be used to measure the accuracy of the shot penalty for hockey players because it shows a fairly high level of reliability.

Based on the results of the above calculations, it can be seen that all forms of proper penalty shot tests are used to test the accuracy of penalty shots for hockey players, because all the results of the test results obtained are significant for testing the accuracy of penalty shots for hockey players [10].

The form of test 2 which explains that most of the shots in the upper left corner and lower right corner have the highest level of validity and reliability among other forms of penalty shot tests, with a validity value of $t$ count $=4.853$ greater than $t$ table $=2.763$, and reliability of $t$ count $=0.710$ is greater than $t$ table $=0.478$. So the author chose the form of test 2 as a form of test that was significant, feasible and suitable to be used to measure the test of the accuracy of penalty shots.

\section{CONCLUSION}

The conclusions from the research conducted were not all of them had good validity and reliability to use, and it was seen from the results above, that the forms of tests 1 and 3 had lower levels of validity and reliability than the test form 2 , so that the test forms were not good as a test of the accuracy of penalty shots for junior high school students, while the form of test 2 is more feasible and meets the criteria to be used as a measure of the accuracy of penalty shot shots for junior high school students in hockey sports.

\section{REFERENCES}

[1] M. Alexander, "Penalty stroke technique," Counterattack, vol. 5, no. (2), pp. 3-10, 1985.

[2] Ausiie Sport Coaching Program, Level 0 Coaching Manual. Australia: Tecprin, 1991.

[3] FIH, Rules of hockey. Lausanne, Switzerland: FIH, 2010.

[4] International Hockey Federation, Rules of Hockey 2000. Brussels: International Hockey Federation, 2000.

[5] M.J. Jennings, I. Blanchonette, S.R. Lucas, S.W. Morgan, R.J.N Helmer, and C. Yang, "Instrumentation of a field hockey stick to detect stick and ball interaction during a drag flick," Procedia Engineering, vol. 2, pp. 2979-2984, 2010.

[6] C. Jhon, Hockey The Skill Of The Game. Redwood Books, 1993.

[7] Pengda FHI Jawa Barat, Peraturan Permainan Hockey Lapangan. Bandung: FHI JABAR, 2007.

[8] Y. Pribadi, Kontruksi Tes Tembakan Penalti Dalam Permainan Hoki. Bandung: Universitas Pendidikan Indonesia, 2005.

[9] C.M. Taverner, "Field Hockey Techniques \&bTctics," 2005. [Online]. Retrieved from: http://www.book.google.co.id/book Accessed on 10 Februari 2010

[10] D. Southard, "Changes in limb striking pattern: Effects of speed and accuracy," Research Quarterly for Exercise and Sport, vol. 60, pp. 348356, 1989. 